\title{
Sob céus estranhos: o exílio segundo Ilse Losa
}

\section{Resumo:}

O texto propõe-se analisar as representações do exílio em três romances da escritora portuguesa Ilse Losa (1913-2006): O mundo em que vivi (1949), Rio sem ponte (1952) e Sob céus estranhos (1962). Apoiando-se na transdisciplinaridade que o estudo das temáticas da migração e do exílio reclama e aproveitando alguns dos contributos teóricos do pós-colonialismo histórico e crítico, assim como os atuais questionamentos sobre os desafios éticos e multiculturais que a sociedade contemporânea enfrenta, o artigo pretende examinar de que maneira as narrativas em foco representam o fenómeno do exílio e, em especial, a identidade do exilado.

Palavras-chave: exílio, migração, refugiados, identidade, Ilse Losa

\section{Abstract: \\ Under Strange Skies: Exile According to Ilse Losa}

The article focuses on how exile is presented in three novels by the Portuguese author Ilse Losa (1913-2006): The World I Lived in (1949), River without a Bridge (1952), and Under Strange Skies (1962). Through the application of the transdisciplinary method while examining the subject matter of migration and exile, the article, on the one hand, utilizes some theoretical contributions to postcolonial studies and finds its place within the present-day discussion about the ethical and multicultural challenges that modern society faces, and on the other examines the way Ilse Losa's novelistic narratives construct the image of exile and how the exiles understand their own identity.

Keywords: exile, migration, refugees, identity, Ilse Rosa 
A história dos movimentos migratórios em que Portugal é ponto de partida ou de chegada tem demonstrado que a migração é um fenómeno que marca de forma intensa a vida da sociedade portuguesa e das suas derivações diaspóricas nos cinco continentes. No intuito de repensar e redefinir a condição do migrante, a ficção literária moderna e atual tem vindo a problematizar a sua identidade e o seu lugar no mundo. Escolhendo a temática da migração e do exílio a partir de finais dos anos 40, a obra romanesca de Ilse Losa ocupa um lugar singular no espaço da ficção portuguesa de Novecentos. Ao tematizar reiteradamente nos seus textos um conjunto de questões vinculadas particularmente à imigração, chegando assim a construir uma expressiva representação ficcional do imigrante, os romances da escritora antecedem com algumas dezenas de anos as ficcionalizações de histórias de imigrantes em Portugal, de que na nossa atualidade literária já há uma série de obras notáveis.

Parece-me oportuno relembrar aqui a vida e o conjunto da obra de Ilse Losa, sobretudo tendo em conta a insistente evocação das circunstâncias biográficas da autora nos seus livros de ficção e de crónicas. A escritora nasce na Baixa Saxónia em 1913, numa família de origem judaica. Os seus anos estudantis transcorrem nos liceus de Osnabruk e Hildeshaim e no Instituto Comercial de Hanôver. Sob ameaça de ser deportada para um campo de concentração após a chegada de Hitler ao poder, vê-se obrigada a fugir da Alemanha. De início escolhe como destino a Inglaterra, onde trabalha como precetora de meninos. Em 1934 muda-se para Portugal que a acolherá como segunda pátria. Fixa-se no Porto e, embora nascida na Alemanha, produz a sua obra em português. Dedica-se à escrita ficcional, à tradução literária, à organização de antologias e livros escolares. É autora de romances, contos, crónicas, sendo de destacar muito especialmente o seu contributo no campo da literatura infantojuvenil. Em 1984 é premiada com o Grande Prémio Gulbenkian pelo conjunto da sua obra para crianças. Em 1998 o seu livro de crónicas À flor do tempo recebe o Grande Prémio de Crónica da APE. Falece no Porto em inícios de janeiro de 2006 (dados biobibliográficos mais detalhados em Rocha, 1998). 
Os romances de Ilse Losa que aqui gostaria de apresentar constituem uma espécie de ciclo da migração e do exílio na obra da escritora. Trata-se de três romances que a autora publica nos primeiros anos da sua carreira literária: $O$ mundo em que vivi, cuja primeira edição data de 1949, Rio sem ponte, de 1952, e Sob céus estranhos, de 1962. Neste ciclo temático, os biografemas da origem judaica, da fuga da Alemanha nazi e do penoso destino de refugiado e imigrante afloram à superfície dos textos, inscrevendo-se decisivamente no conjunto de tópicos que a escrita de Ilse Losa vai problematizar ao longo dos anos ao enfocar a perseguição e o genocídio dos judeus pelo Terceiro Reich e, em paralelo, a procura de asilo e a árdua construção de uma nova vida num país estrangeiro.

Antes de abordar os textos gostaria de contextualizar no seu quadro histórico-social a ação dos romances que aqui nos interessam. Referirei alguns dados sobre a migração da população europeia de origem judaica para Portugal durante a década de 30 do séc. XX e a Segunda Grande Guerra, apoiando-me em investigações produzidas nos últimos anos no âmbito da história política e social.

Após a chegada ao poder do nacional-socialismo na Alemanha, o antissemitismo feroz do Terceiro Reich desfigura o rosto da Europa, desencadeando uma onda de discriminação desumana e monstruosa violência. Na sua fuga em massa dos territórios ocupados pelos nazistas, a população de origem judaica dirige-se aos países que mantêm neutralidade no conflito. Devido sobretudo à neutralidade, mas também por causa de outros fatores, Portugal exerce uma forte atração para os que procuram refúgio. Ao analisar o papel do cônsul português em Bordeaux Aristides de Sousa Mendes ${ }^{1}$ na salvação de milhares de famílias judaicas durante a Segunda Grande Guerra, Rui Afonso descreve a posição geoestratégica da capital portuguesa naquela altura da maneira seguinte: "Lisboa tinha-se convertido no único porto no

${ }^{1}$ Como cônsul português na cidade francesa, Sousa Mendes (1885-1954) emite sob sigilo e apesar da proibição do seu governo, milhares de vistos a famílias judaicas em fuga, pelo que é destituído do cargo e posteriormente sofre repressões por parte do regime salazarista. 
continente que contava com ligações relativamente regulares com as duas Américas e com a África. [...] Para a Europa, a capital portuguesa era uma saída de emergência" (Afonso, 1995: 49). Na sua abrangente investigação sobre os fluxos migratórios de judeus no período entre a Primeira Grande Guerra e a Guerra Fria Michael Marrus dedica uma atenção especial aos roteiros de fuga durante a Segunda Guerra Mundial e às políticas de Espanha e Portugal, que se mantêm à margem do conflito, em relação aos cidadãos europeus de origem judaica expatriados da Alemanha e dos territórios ocupados pela Wehrmacht, aduzindo dados impressionantes sobre a quantidade de pessoas que se dirigem ao Porto, a Lisboa, Coimbra, Caldas da Rainha, Figueira da Foz e Ericeira à procura de uma oportunidade para cruzar o Atlântico, em direção à América Latina ou aos Estados Unidos (cfr. Marrus, 2002: 258-264).

Sendo uma periferia isolada do Velho Continente que se vê na situação forçada de acolher um fluxo considerável de refugiados de diferentes nacionalidades, maioritariamente de origem judaica, Portugal tem de enfrentar uma realidade que lhe é completamente desconhecida e que possui implicações humanitárias e socio-políticas particulares, a que o poder e a sociedade reagem de forma ambígua. Os testemunhos históricos põem em evidência o facto de que, excetuando as organizações germanófilas que simpatizam com o nazismo e os círculos nacionalistas vinculados ao regime salazarista, a população portuguesa manifesta sentimentos de compaixão e solidariedade em relação aos imigrantes judeus (cfr. Pimentel, 2006). Deve-se sublinhar que a postura do Estado Novo de Oliveira Salazar no que concerne à questão dos refugiados não se pode definir como uma política programática e específica em relação à imigração e ao seu controlo efetivo, que seja marcada pela xenofobia e pelo antissemitismo. Uma série de estudos confirma que no período entre 1933 e 1939, apesar da crescente pressão migratória, o governo português não chega a efetuar alterações legislativas que possam regular restritivamente o trânsito dos refugiados judeus pelo território português e o seu acolhimento, mas apenas aplica medidas de ocasião que funcionam a curto prazo e em resposta concreta à pressão migratória num ou noutro momento com vista 
a dificultar a fixação desses refugiados no país e assim proteger a mão de obra nacional do extraordinário afluxo de estrangeiros ao mercado. Com a consolidação da ideologia nacionalista do Estado Novo e do seu caráter repressivo após 1935 tais medidas são endurecidas ao ponto de se transformarem em intransponíveis obstáculos administrativos para a emissão de vistos àqueles que o regime considera estrangeiros "indesejados" e "perigosos" (cfr. Alves, Faria, 2010). Apesar de tais restrições, a política portuguesa de não fechar as fronteiras aos refugiados que desejam transitar pelo país com destino a outros países, tanto antes, como durante a Segunda Grande Guerra, contribui para a salvação de milhares de pessoas de origem judaica que, ficando nos territórios ocupados pela Alemanha nazi, seriam condenadas à perseguição e ao extermínio.

Nos seus estudos sobre a história da diáspora judaica em Portugal Irene Pimentel e Ester Mucznik aludem a documentos oficiais e testemunhos variados acerca da receção dos primeiros refugiados que chegam da Alemanha em 1933. Os dados fornecidos permitem concluir que o Estado Novo, naquela altura recentemente institucionalizado, acolhe os refugiados judeus com uma tolerância relativa. Tal tolerância expressa-se não apenas na permissão para entrarem em território português àqueles que procuram asilo provisório, mas também no consentimento do governo para que no país funcionem organizações judaicas de apoio, locais e estrangeiras ${ }^{2}$.

Não devem deixar de ser consideradas, por outro lado, as apreensões do regime salazarista em relação aos refugiados de origem judaica, o que motiva as medidas de restrição e repressão aplicadas aos exilados pelos Ministérios do Exterior e do Interior e pela Polícia de Vigilância e Defesa do Estado. De que apreensões se trata? Nos anos 30 do séc. XX a comunidade judaica em Portugal, a habitar o território

${ }^{2}$ As investigadoras estudam o papel de todas as organizações de apoio aos judeus refugiados em Portugal que atuam no país desde a década de 30 até aos anos 50 do séc. XX, prestando especial atenção à Comissão Portuguesa de apoio aos refugiados judeus (COMASSIS), à Cozinha Económica, ao Hospital Israelita, à Organização Internacional de apoio a migrantes europeus judeus (HICEM), e ao Comité Judaico-Americano de distribuição de doações (JOINT). 
continental e as colónias africanas, é composta predominantemente por famílias sefarditas retornadas da África do Norte em finais do séc. XIX, cujos antepassados para lá haviam migrado de Portugal e Espanha na época da expulsão dos judeus da Península Ibérica nos finais do séc. XV e inícios do séc. XVI. Insignificativa em número, esta comunidade é demograficamente irrelevante e até "invisível" devido à sua quase completa integração na sociedade portuguesa, como afirma Pimentel (2006: 41). Os receios de alguns representantes do governo salazarista consistem em que, ao ser liberalizado o acolhimento de exilados judeus, a minoria judaica no país poderia aumentar - pois só no período entre a capitulação de França em junho de 1940 e meados de 1941 em Portugal entram, vindos do território francês, mais de 50 mil refugiados, muitos deles com os vistos emitidos por Sousa Mendes em Bordeaux - e que isto por sua vez poderia provocar o surgimento da "questão judaica" em Portugal (cfr. Pimentel, 2006: 41-44). A posição categórica do governo português de não querer que a questão seja sequer discutida explica-se pela firme matriz católica do salazarismo que rejeita abertamente as teorias eugénicas que estão na base da doutrina do nacional-socialismo alemão. Os dados confirmam que a maioria dos judeus que se refugiam em Portugal emigram posteriormente para outros portos de salvação. Os que fixam residência no país representam um número relativamente reduzido e a sua integração na sociedade portuguesa conduz a apenas uma mudança - na composição predominantemente sefardita da comunidade judaica local entram mais famílias asquenazes, como o assinalam os estudos da história da diáspora judaica em Portugal (cfr. Mucznik, 1999).

Os romances de Ilse Losa são o testemunho ficcional dessa complexa realidade histórica, política e social que acabamos de traçar a pinceladas grossas - a realidade contraditória e dramática resultante do êxodo de milhares de pessoas de diversas nacionalidades europeias e de origem judaica. As obras aqui em apreço inscrevem no seu espaço textual a memória das origens e da tradição, o trauma do êxodo e do Holocausto, a alienação do exílio - mas também inscrevem a esperança de continuar a viver, de ter uma vida nova num novo país, de se integrar entre a sua gente e de ser feliz. A seguir tentarei abordar 
sucintamente os dois primeiros romances, que poderíamos designar como o romance "alemão" e o romance "inglês" do ciclo do exílio, para focar depois, de forma mais pormenorizada, o terceiro romance do ciclo, Sob céus estranhos, cuja ação já se desenvolve no espaço português.

O mundo em que vivi, que aparece em 1949, reimpresso em mais de 30 edições até ao momento, é o romance de estreia da autora. A história pessoal da jovem Rose Catarina Frankfurter é permeada de referências à história coletiva que situam a ação no período entre os últimos anos do governo do Kaiser Guilherme II e os princípios do Terceiro Reich. Acompanhando por meio de uma cronologia linear os acontecimentos na família da protagonista, a narrativa constrói-se na base da oposição entre uma infância inocente, placidamente transcorrida na província alemã, e uma juventude de dramatismo crescente que culmina na fuga de Berlim para salvar a vida e na dolorosa consciência do trágico e irrevogável destino do seu povo. Tanto na narrativa principal como nas micronarrativas que nela se enquadram, $O$ mundo em que vivi anuncia temas, cujo tratamento será aprofundado pelos romances que continuam o ciclo: o antissemitismo, o ódio racial, o militarismo, a culpa histórica da nação alemã. O desfecho do romance é de certa forma inesperado, pois deixa supor a salvação de Rose no meio de queimas, apedrejamentos, prisões, torturas, deportações e mortes. A protagonista parece recuperar a dignidade humana de que há pouco fora privada, e com essa dignidade regressa a esperança de poder sobreviver em vez de se tornar vítima como tantos outros ao seu redor. Analogamente ao que acontece à Ilse Lieblich, Rose ficará a salvo ao fugir da Alemanha nazi. Assim, o romance formula no seu final uma mensagem de fé, esperança e solidariedade, lançando uma ponte para o segundo romance do ciclo. Transcrevo a seguir as últimas linhas de O mundo em que vivi:

Alexanderplatz. O mar da multidão que me absorve, a mim, a gota insignificante, que vivia, respirava, via o céu, o sol. Ao meu lado, diante de mim, atrás de mim, corpos, rostos, vozes. Gente como eu. Mas ninguém 
sabe que a minha vida esteve em jogo poucos minutos antes, que eu, Judia

Frankfurter, tenho cinco dias para deixar o país (Losa, 2011: 196).

Rio sem ponte (1952) continua a exploração temática geral da migração e em particular do êxodo judeu durante a Segunda Grande Guerra. A desolação do ser migrante insinua-se desde o limiar do texto pelo título metafórico que, se por um lado remete para a solidão e o isolamento do migrante na brumosa cidade nas margens do Tamisa, por outro refere o destino arriscado e incerto do exilado, arrastado pelo violento caudal do processo histórico, sem ponte a que se agarrar, sem nenhuma oportunidade que lhe abra o caminho e o conduza à outra margem, a da salvação. $\mathrm{O}$ romance relata a história dos jovens apaixonados Jutta Berner e Johann Schuster, que se desenvolve no quadro da existência tumultuosa dos seus ambientes sociais. A partir da separação de Jutta e Johann, a ação passa a decorrer paralelamente em dois espaços: em Inglaterra, para onde emigra Jutta, que fugindo ao desemprego na pátria vai trabalhar como precetora dos filhos de uma família judia dos arredores de Londres, os Finkelberg, e na Alemanha, onde fica o seu noivo. Incorporando na narrativa biografemas da autora, o romance põe em foco as primeiras tentativas de emigração da Alemanha nazi, ainda possíveis na década dos anos 30 de Novecentos, para explorar a fundo a condição do migrante.

A representação da migração que Rio sem ponte constrói é múltipla. A migração é encarada como um desejo de alargar os horizontes da vida, mas também como saída forçada, ou, quando necessário, como uma escolha ética que o indivíduo efetua já não em nome da sua sobrevivência física mas da sua integridade moral. Ao saber pelas cartas do noivo da violência nazi desencadeada na Alemanha contra os judeus e os que se opõem ao partido nacional-socialista, Jutta desiste do regresso à pátria que antes tanto desejara, enquanto Johann foge para a Suíça, aspirando reunir-se mais tarde com Jutta em Inglaterra. De novo, como no romance anterior, o final da narrativa promete um desfecho feliz para os exilados, porque o exílio e a andança de terra em terra afinal também fazem parte do infindável e incerto caminhar do ser humano em busca da felicidade: 
Ainda por toda a parte nevoeiro. Caminhos cobertos de lama. Mal se distinguiam os braços nus que as árvores erguiam contra o céu. No coração de Jutta revezavam-se as lágrimas com a alegria.

Ficaria em terras estranhas. Não veria a mãe. Nem a cidade e os montes. Mas, dentro de horas, Johann estará a seu lado. Johann, que era o seu lar e o seu regresso!

Nada planearam ao certo. Talvez ficassem aqui. Talvez seguissem para outra terra. Talvez. Talvez... (Losa, 1998: 177).

Sob céus estranhos (1962) conclui o ciclo de romances na obra de Ilse Losa que tematizam a migração. O paratexto avança de forma transparente e incontestável o tema maior neste romance - o do exílio. A narrativa é antecedida por uma epígrafe poética dupla que, tanto no seu aspeto visual como na sua dimensão significativa, consegue o efeito daquela tensa simetria entre espaços e mundividências que a temática da migração pressupõe. A primeira epígrafe é constituída pelos versos de Rafael Alberti e a segunda - pelos de Hilde Domin, dois poetas que recriam na sua obra e experiência do exílio. Os acentos temáticos nos versos do poeta ibérico, citados no seu original em espanhol, são a universalidade do ato criativo como também a sua profunda ligação com a terra de origem, ainda que as raízes sejam cortadas. Os versos da poeta alemã, na tradução de Ilse Losa, apontam como imperativos essenciais do ser humano migrante a coragem de ultrapassar os reveses do destino e a sabedoria de se adaptar à terra estranha como se fosse sua.

A estrutura circular da narrativa faz a ação começar no momento em que o protagonista José espera, no corredor da maternidade, o nascimento do seu primeiro filho e acabar quando, já pai, José tem a criança nos seus braços. Entre o primeiro e o último episódio realiza-se uma ampla retrospeção da vida de José, que cruza habilmente vários planos temporais e conjuga em interseção diferentes espaços. Os momentos cruciais do destino do protagonista lembram inequivocamente as fábulas dos dois romances precedentes: a juventude na Alemanha natal, a fuga do terror, a vida de refugiado num país estranho e hostil, a difícil adaptação do exilado. O protagonista Josef Berger, filho de 
pai judeu e mãe protestante, é um apátrida. Privado da nacionalidade alemã, o refugiado fica em Portugal após várias tentativas frustradas de seguir para os Estados Unidos, onde o espera seu irmão. O discurso narrativo hesita entre a neutralidade de uma terceira pessoa, que conduz distanciadamente a narração nos episódios inicial e final, e a primeira pessoa que impõe a perspetiva interna não apenas para acompanhar de perto o dia a dia do refugiado e relatar outras vidas que se cruzam com o seu destino, mas também para trazer à superfície as vivências traumáticas do exílio, da alienação, da culpabilização e da resignação.

Retomando temas e motivos que já conhecemos dos romances anteriores, Sob céus estranhos completa com um dramatismo acentuado a construção da representação do migrante e, em particular, do exilado. A sua figura desenha-se pela presença de personagens secundárias marcadamente individualizadas que têm em comum a origem judaica e a condição de apátridas: o sábio octogénario Samuel Sperberg, o escritor frustrado Egon Frank, o poeta Goldberg, a viúva Grunbaum, a apaixonada e infeliz Hanna Mundel, assim como vários outros personagens episódicos que também funcionam como emblemas do sofrimento no exílio. Vindos de Berlim, Praga, Varsóvia, Munique, Viena, Hamburgo, e a ansiar poder chegar ao Brasil, aos Estados Unidos, ao Uruguay, à Argentina, à Venezuela, ao Equador ou à Austrália, todos estes refugiados levam uma existência precária em Portugal, onde os seus dias, norteados pelo imperativo da sobrevivência, transcorrem sob o signo da solidão, da inadaptação e do desespero.

Impõe-se assinalar a dimensão sem dúvida testemunhal do romance de Ilse Losa, que recria ficcionalmente o quadro complexo da situação dos refugiados em Portugal, antes e durante a Segunda Grande Guerra, com ênfase especial nos aspetos políticos, económico-sociais, psicológicos e identitários que caracterizam essa dramática situação. Gostaria de citar aqui as palavras de Hommi Bhabha, outro exilado, embora em outros tempos e lugares. O seu testemunho pessoal parece falar em nome de todos os refugiados e exilados, reais e fictícios, e entre os últimos incluimos também os personagens de Ilse Losa, que se reúnem no café Superba para partilhar a solidão dos marginalizados, 
confidenciar o sofrimento e dar apoio a amigos ou desconhecidos que nada têm a não ser a mesma condição de infelizes. Eis as palavras de Hommi Bhabha:

Vivi aquele momento de dispersão de povos, que em outros tempos e em outros lugares, nas nações de outros, transforma-se em tempo de reunião. Reuniões de exilados, émigrées e refugiados, reunindo-se às margens de culturas estrangeiras, reunindo-se nas fronteiras; reuniões nos guetos ou cafés de centros de cidade; reunião na meia-vida, meia-luz de línguas estrangeiras, ou na estranha fluência da língua do outro; reunindo os signos de aprovação e aceitação, títulos, discursos, disciplinas; reunindo as memórias de subdesenvolvimento, de outros mundos vividos retroativamente; reunindo o passado num ritual de revivescência; reunindo o presente. (Bhabha, 1998: 198).

A imagem coletiva do exilado que Sob céus estranhos constrói surge aos olhos do leitor duplamente refratada: ora através da perspetiva especular que o narrador protagonista adota, autodefinindo-se como exilado ao fazer a observação dos outros exilados, ora desviada da sua profunda essência humana ao se constituir como a imagem externa dos estrangeiros fugidos e errantes que os portugueses imaginam. O romance consegue captar com veracidade e notável minuciosidade psicológica os múltiplos e contraditórios conteúdos da vivência do exílio, incluindo, entre eles, o conceito que o exilado tem de si próprio e o outro, por vezes contrário, que dele tem a comunidade local, como se pode observar em Sob céus estranhos. Inserindo no tecido narrativo do romance a referência às políticas institucionais do estado português e de outros países em relação aos refugiados, a ação acompanha o andar sem rumo dos apátridas, a sua errância entre os consulados estrangeiros, as tentativas fracassadas de conseguir um visto temporário para ficar em Portugal, a detenção dos que prorrogaram o seu direito de permanência nas prisões lisboetas ou o internamento nas Caldas da Rainha até ao fim da guerra. Não são poucas as passagens do livro que oferecem o testemunho de que a sociedade portuguesa dos anos 30 e 40 de Novecentos, fechada no seu atraso e acomodada à ignorância da verdade sobre o que se passa na Europa, rejeita de 
diversas formas e graus - com preconceitos e suspeitas infundadas, com clara xenofobia ou simplesmente com indiferença - os refugiados que estão a afluir a Portugal, vindos de todos os lados do continente. Citarei apenas um exemplo:

$\mathrm{O}$ bicho enorme, essa multidão que formigava pelas ruas, amorfa, mole e frouxa, vencida pela inércia social a que a cidade se tinha encostado e que se acentuava agora pela presença dos intrusos vindos nem se sabia de onde nem como: apresentavam-se de vestuário excêntrico e tão gasto que comovia, ou de trajes magníficos de causar espanto; chegavam a pé, de mochila às costas ou no "rápido", com malas de couro. [...] Essa gente estranha, espalhada pelos cafés e pelas praias, a levar uma vida de nómada, quase de ciganos, destoava do ambiente e criava uma atmosfera de instabilidade, incerteza e angústia. Não se estaria tão seguro na sela como se tinha suposto? Poderia alguma ventania sacudir as velhas fachadas e demoli-las? (Losa, 2000: 62).

Após esta citação extraída de um texto escrito no início dos anos 60 do século passado, a revelar a memória então ainda viva dos que testemunharam o maior conflito armado na história da humanidade, não posso deixar de citar outro texto, escrito na nossa atualidade e dedicado à grande vaga de refugiados à porta da Europa. As palavras que aqui queria lembrar são da autoria de Zygmunt Bauman:

Refugiados da barbárie de guerras e regimes despóticos ou da crueldade de uma existência miserável e sem perspetivas têm batido a portas estranhas desde os inícios da época contemporânea. Para as pessoas por trás dessas portas eles sempre foram - e continuam a sê-lo ainda - intrusos. (2017: 13-14).

A uma distância de pouco mais de meio século Bauman formula no seu ensaio a mesma convicção que já identificamos na narrativa ficcional de Ilse Losa - sobre a desumanidade das sociedades de acolhimento que não apenas reduzem os refugiados a intrusos, mas que com a sua indiferença e rejeição os condenam ao isolamento, à degradação social e à perda de dignidade humana. 
Alguns dos exilados de Sob céus estranhos pretendem a integração e tentam estabelecer laços duradouros com a comunidade local no desejo de ganhar o seu reconhecimento, pois percebem que só a integração lhes assegurará a sobrevivência física e espiritual. É o caso do protagonista Josef que, adotando deliberadamente o nome português José, faz um esforço para se incorporar nas microssociedades por onde transita: as pensões do Sr. Sousa, de Dona Adelaide e de Dona Branca, o círculo intelectual do pintor Gil Roseira. O seu casamento com Teresa, a portuguesa que o ama sem condições, confirma definitivamente nele a aspiração de ver-se integrado no país que o acolhe, apesar dos sentimentos contraditórios que experimenta em relação à realidade portuguesa que considera fechada e provinciana. Independentemente da resolução de se integrar no espaço português, este Josef que já é José, ou José que ainda é Josef, não deixa de conceber-se como parte da comunidade de refugiados. Eis o que reflete o seu olhar quando observa no grande espelho do café Superba os expatriados recém-chegados à cidade:

...essa gente, à mesa do Superba, tão heterogénea, sempre igual e sempre outra, dominada pelo único desejo de se refugiar, sobreviver, permanecer e com quem eu, quem sabe?, devia ter partido, de terra em terra, porque era a eles, aos expatriados à procura de uma pátria que eu pertencia... (Losa, 2000: 163).

A sensação de falta de pertença está no âmago da fatalidade a que se vê condenado o exilado. Apesar de passar a chamar-se José, ele sabe que nunca se adaptará a um país que continuará a sentir como estrangeiro, um país que para ele é um "pachorrento pedacinho de terra, na última ponta da Europa, a dar a ideia de já não pertencer à Europa" (Losa, 2000: 78). A consciência da alienação do protagonista insinua-se-lhe até nos momentos mais entranháveis que ancoram a sua vida em Portugal - no dia do seu casamento e no instante em que toma nos braços o filho recém-nascido.

O estranhamento é muito mais forte e até irremediável em relação aos seus compatriotas alemães, chegando ao extremo de provocar a negação duma pertença comum à mesma nação. Os romances 
anteriores já articulavam o discurso anti-nazi a plena voz, mas Sob céus estranhos expressa a gritos o protesto, a indignação, o horror e a dor provocados pelos atrozes crimes perpetrados em massa pelo nazismo. A rejeição de qualquer identificação com o alemão, explicita-se em momentos decisivos da ação como por exemplo durante a visita ao consulado americano, quando Josef é interrogado sobre a sua identidade nacional, ou no recorrente discurso introspetivo. O trauma do genocídio, daquela monstruosa violência que "o colapso de humanidade generalizado", para usar a expressão de Bauman (2011: 256), provoca no protagonista a rejeição daquela identidade coletiva que o identificaria com o povo que permitiu que tal violência acontecesse. Daí o estigma do apátrida voluntário que Josef carrega na sua consciência. Citarei aqui dois exemplos textuais, simetricamente posicionados no início e no fim da narrativa, confirmando assim a opção ética do protagonista de não pertencer mais à nação que o vira nascer e crescer e depois o fizera fugir para salvaguardar a vida. O primeiro exemplo inscreve-se na reflexão rememorativa de José, que decorre durante a sua espera no corredor na maternidade:

Eu seria diferente sem os fanáticos desumanizados que me agrediram num tranquilo dia de primavera. A sua brutalidade vive em mim, viverá sempre em mim, mas a minha inocência daquele momento, a dor e a minha solidão, por sua vez, vivem neles, por mais rudes e duros que possam ser. Seria outro se não soubesse do massacre de inocentes que os meus compatriotas levaram a cabo. Porque, se eu o não soubesse, como poderia imaginar que eles eram capazes de organizar tal carnificina, se sempre os vira sorrir com ternura para as crianças? Se para eles, como para toda a gente, a criança representava uma esperança coletiva, um sentimento inefável: a nostalgia, as oportunidades perdidas, tudo aquilo que poderia ter sido e poderia ainda ser: a outra possibilidade. Tudo isso os comovia, aos meus compatriotas. Assim, quem os teria julgado capazes de matar crianças? E posso eu ser o mesmo depois de ter conhecimento de que mataram crinças e de tudo aquilo de que os homens são capazes? Depois de me perseguirem em sonhos as imagens daquele menino - seis anos, sete anos? - de boné, blusão e soquetes, olhos aterrorizados, as mãos ao ar? 
Mãos ao ar!, e o soldado: botas, essas medonhas botas cujo bater rítmico, disciplinado, não deixa de ressoar nos meus ouvidos, pernas robustas, apartadas com arrogância, espingarda apontada para o menino: mãos ao ar! E os mirones em volta, indiferentes ou a rir, sem se envergonharem daquela situação absurda, cobarde, infame... (Losa, 2000: 17-18)

O segundo exemplo, em absoluta correspondência com o primeiro, reafirma, já no final do romance, a negação de Josef de possuir uma identidade comum com os seus compatriotas alemães. O trecho, que mais à frente citarei, clama contra os crimes nazis e acusa os que participaram ou foram testemunhas passivas das atrocidades. O romance de Ilse Losa explora assim, no início dos anos 60 de Novecentos, um tema particularmente sensível que ecoa não só nos anos posteriores à guerra, mas também muitos anos depois - o da culpa histórica da nação alemã. Relacionando esta questão com o ideal social que norteia o estado totalitário e que se identifica com o ideal do domínio absoluto de uma nação, Hannah Arendt afirma no seu estudo capital que "a antiga atrocidade espontânea cedeu lugar à destruição absolutamente fria, insensível e sistemática dos corpos humanos" e que "o alemão começou a obedecer à máquina da destruição sem sequer oferecer resistência" (2006: 184-185). Na sua análise dos fenómenos sociais que tornaram possíveis a modernização da crueldade e o século dos campos de concentração Zygmunt Bauman assinala que a modernidade inventou a maneira pela qual as atrocidades podem ser executadas por pessoas que não são em si atrozes e que esta maneira consiste em "a separação das ações da ética, daquilo que as pessoas fazem do que elas sentem e em que acreditam, i.é. na disjunção entre a natureza das ações coletivas e os motivos dos agentes individuais" (Bauman, 2011: 260). As palavras de Bauman sobre a crueldade modernizada, generalizada, perfeitamente executada por pessoas que em princípio não são más - e essas palavras soam em uníssono com as de Ilse Losa, que mais à frente citarei, - são as seguintes:

Precisamente essas pessoas pacíficas que respeitavam as leis, que eram trabalhadores disciplinados, esposos e pais de família exemplares, 
executavam juntos ou permitiam que fosse perpetrado um crime sem par na história da humanidade. (Bauman, 2011: 257)

Três anos depois de terminada a guerra o protagonista de Sob céus estranhos retorna à Alemanha para mostrar à sua esposa portuguesa a beleza da terra natal, mas o que encontra é "uma terra impregnada de cheiro a crime" (Losa, 2000: 133). Quando Josef vê as cidades que rapidamente se recuperam da destruição causada pela guerra e encontra os sobreviventes, o seu entusiasmo pelo regresso cede lugar à memória ressuscitada do crime contra a sua etnia. A recusa de se identificar com o país que outrora, antes do exílio, fora sua pátria, recusa já manifesta na narrativa, como vimos, atinge agora a sua expressão suprema. Estrangeiro no país que o acolhe, José percebe-se estrangeiro também no lugar em que nasceu. Fazendo notar a atmosfera social do período pós-guerra, impregnada da retórica dos valores do cristianismo e da cultura ocidental, a narrativa apresenta-nos um José que confessa que nada lhe dá a sensação de um retorno desejado e feliz. A acusação e a recusa do perdão impõem-se emotivamente no final do romance, como o demonstra o trecho que passo a citar:

Ninguém parecia ter escorraçado ninguém. Fora então um medonho pesadelo o grupo do Superba, sempre diferente, sempre o mesmo e sempre em fuga, as corridas para os consulados para se obterem vistos, os cais apinhados de gente difamada e humilhada, os barcos superlotados, os suicídios, o terror, o medo? Ninguém parecia ter assassinado ninguém. E nenhuma daquelas pessoas solícitas tinha cara de assassino de crianças. Lamentavam, sentiam muito, algumas até choravam. Mas não se apresentou um único que se confessasse presente nos dias da carnificina. Estiveram ausentes, todos. (Losa, 2000: 173)

No último capítulo de Sob céus estranhos, que se apresenta à maneira de um epílogo, José, o apátrida, finalmente parece chegar ao seu porto seguro, descobrindo os seus próprios traços no rostinho do filho que lhe acaba de nascer. Ao amanhecer, enquanto vigia o sono da mulher e do filho e respira pela janela aberta o ar lavado pela chuva, José, que antes se concebera como aquele que "uma vez foi condenado 
a fugir" e "nunca mais será senão um fugitivo, que tem de fugir de si próprio... ou da pátria" (Losa, 2000: 173), agora pensa:

Um filho é continuação. Ou chegada? Procura chegar, José! Procurei chegar [...] procurei deveras. Mas sabes tu o que quer dizer chegar? $\mathrm{O}$ amor a outros seres, a continuação em outros seres, a ilusão de segurança e de estabilidade ou somente uma estação intermédia na eterna fuga do homem? Não sei, não sei... (Losa, 2000: 182).

A ambiguidade que a autorreflexão do protagonista gera no final do romance nutre-se da dúvida de José se deverá ou não persistir na sua errância. Ficar no país de que não gosta, mas a que já o ligam os fortes laços da sua família portuguesa, ou prosseguir para a América, que continua a chamá-lo com a voz do irmão que lá o espera, ou para São Paulo, ou para outra cidade cosmopolita e por isso atraente - este é o seu dilema. Mesmo assim, essa cena final, impregnada de sugestões simbólicas que remetem à matriz judaico-cristã, e concretamente aos tópicos do Sagrado Menino e da chegada do Messias, vem anunciar a vitória do futuro sobre o passado, da vida sobre a morte, para formular de novo aquela mensagem de salvação com que invariavelmente acabam os romances do ciclo do exílio de Ilse Losa.

\section{Referências bibliográficas}

AFONSO, R. (1995), Um homem bom: Aristides de Sousa Mendes, o "Wallenberg Português", Editorial Caminho, Lisboa.

ALVES, V., FARIA, S. (2010), "Refugiados da II Guerra Mundial em Portugal”, Sapiens: História, Património e Arqueologia, 3/4 (Dezembro), pp. 40-65, [on-line] http://www.revistasapiens.org/Biblioteca/numero3_4/ refugiados_da_II_guerra_mundial.pdf-18.07.2016.

ARENDT, H. (2006), As origens do totalitarismo, Dom Quixote, Alfragide. BHABHA, H. K. (1998), O local da cultura, trad. M. Ávila, E. L. de Lima Reis, G. R. Gonçalves, UFMG, Belo Horizonte.

BAUMAN, Z. (2011), Vida em fragmentos, trad. A. Werneck, Jorge Zahar Ed., Rio de Janeiro. 
BAUMAN, Z. (2017), Estranhos à nossa porta, trad. por Carlos Alberto Medeiros, Jorge Zahar Ed., Rio de Janeiro.

LOSA, I. (1998), Rio sem ponte, Ed. Afrontamento, Porto.

LOSA, I. (2000), Sob céus estranhos, Ed. Afrontamento, Porto.

LOSA, I. (2011), O mundo em que vivi, Ed. Afrontamento, Porto.

MARRUS, M. R. (2002), The Unwanted. European Refugees from the First World War Through the Cold War, Temple University Press, Philadelphia. MUCZNIK, E. (1999), Os judeus em Portugal. Presença e memória, Sítio da Comunidade Israelita de Lisboa, [on-line] http://www.cilisboa.org/ hpt_esther.htm - 04.01.2019.

PIMENTEL, I. F. (2006), Judeus em Portugal durante a Segunda Guerra Mundial. Em fuga de Hitler e do Holocausto, Esfera dos Livros, Lisboa. ROCHA, I. (1998), Dicionário cronológico de autores portugueses, vol. IV. Organizado pelo Instituto Português do Livro e das Bibliotecas, Ed. Europa-América, Mem Martins. 